\title{
O USO AGRÍCOLA DE ESCÓRIA DE SIDERURGIA EM LATOSSOLO VERMELHO DISTRÓFICO TÍPICO
}

\author{
Ralph Barbosa Rodrigues Alves ${ }^{(a)}$, Idelvone Mendes Ferreira ${ }^{(b)}$, Thaís Abadia Barbosa \\ Rodrigues Alves Figueiredo ${ }^{(\mathrm{c})}$, Rosirlene Lopes da Cruz ${ }^{(\mathrm{d})}$
}

(a) Mestrando em Geografia / UFG - Regional Catalão, E-mail: ralphpmgo@ hotmail.com

(b) Professor Dr. em Geografia / UFG - Regional Catalão, E-mail: idelvoneufg@ gmail.com

(c) Graduação em Agronomia / UFU - Uberlândia, E-mail: thaisabadia@ yahoo.com.br

(d) Mestranda em Geografia / UFG - Regional Catalão, E-mail: rosirlenelopezdacruz@ gmail.com

\section{EIXO: SOLOS E PAISAGENS}

\begin{abstract}
Resumo
A escória de siderurgia, considerada como um passivo ambiental, sendo claramente demostrado pelas usinas siderúrgicas o interesse de sua plena utilização, com composição constituida por diversos óxidos de $\mathrm{Ca}, \mathrm{Mg}, \mathrm{Si}, \mathrm{Fe}$ e $\mathrm{Mn}$. O aproveitamento desses materiais como fontes de $\mathrm{Si}, \mathrm{Ca}, \mathrm{Mg}$ e corretivos de solo é desejável para a agricultura. Uma escória destinada ao uso agrícola, com níveis significantes de Si, deve apresentar teores de Si solúvel com reatividade, facilidade de aplicação (densidade alta), boa relação cálcio e magnésio e teores de $\mathrm{CaO}$ e $\mathrm{MgO}$. Com o objetivo de avaliar este potêncial o presente trabalho realizou a avaliação agronômica de uma escória siderúrgica que foi "aditivada", e seus impactos no solo. Sendo realizada a incubação com Latossolo Vermelho Distrófico típico $(\mathrm{LVd})$. Através do presente trabalho foi possível delinear parametros para o uso de escórias de siderurgia atraves da pesquisa qualitaiva com posterior análise empírica dos resultados.
\end{abstract}

Palavras chave: Escória Aditivada, Passivo Ambiental, Solo.

\section{Introdução}

A escória de siderurgia, um dos resíduos gerados durante a produção de ferro-gusa, considerada como um passivo ambiental, sendo claramente demostrado pelas usinas siderúrgicas o interesse na utilização plena da escória, seja pela extração dos minerais remanescentes, ou como agregados na construção civil, e quando apropriado, conciliado com a atividade agrícola, diminuindo, pelo menos em parte, o passivo ambiental gerado pelo acúmulo de escória nos pátios das siderúrgicas. Sendo incentivada por políticas governamentais voltadas para o desenvolvimento de uma indústria de construção sustentável.

A percepção humana quanto aos desequilíbrios ambientais, proporcionou ao longo dos anos, maior preocupação com a qualidade ambiental, o que gera a necessidade da implantação de alternativas de instrumentos de gestão ambiental com diferentes enfoques a fim de implantar a visão do desenvolvimento sutentável (SEIFFERT, 2009).

A escória de aço é definida como um produto não metálico, constituído essencialmente por silicatos de cálcio e ferro, combinados com óxidos fundidos de ferro, alumínio, manganês, cálcio e magnésio, sendo 
sua forma de utilização, intimamente relacionada com as suas características químicas e físicas (GUIMARÃES, 1967).

Os metais pesados nos solos continuam a receber atenção crescente devido à maior compreensão da sua importância toxicológica nos ecossistemas, na agricultura e na saúde humana, na crescente consciência científica e pública das questões ambientais e no desenvolvimento de técnicas analíticas ainda mais sensíveis para medir as suas concentrações com precisão.

Metais pesados é o termo aplicado para um grande grupo de elementos traço que são tanto industrial quanto biologicamente importantes. Entretanto, não completamente satisfatório de um ponto de vista químico, "metais pesados" é o mais largamente reconhecido e usado termo para o grande grupo de elementos com densidade atômica maior que $6 \mathrm{~g} / \mathrm{cm}^{3}$. Estes elementos são tóxicos para organismos vivos quando presentes em excesso. No entanto, alguns como $\mathrm{Co}, \mathrm{Cr}, \mathrm{Cu}, \mathrm{Mn}$, e $\mathrm{Zn}$ são essenciais para o crescimento de plantas, animais ou ambos. Já os metais pesados que tendem a ser mais preocupantes para saúde humana, agricultura e ecotoxicologia são As, Cd, Hg, Tl e U (ALLOWAY, 1995).

O Brasil é o nono maior produtor de aço bruto no mundo com $2,1 \%$ da produção mundial totalizando 30.212,30 mil toneladas de aço bruto em 2016, sendo Minas Gerais o Estado com maior produção nacional, 10.895,00 mil toneladas, com 34,8\% da produção nacional (IAB, 2016).

"Considerando que em cada tonelada de aço produzido são geradas cerca de $150 \mathrm{~kg}$ de escória de aciaria, o Brasil com uma produção de 31,1 milhões de toneladas gerou somente no ano de 2003 aproximadamente 4,6 milhões de toneladas deste resíduo" (DELLA et al., 2005). Fazendo a mesma comparacão com a produção de 2016, temos aproximadamente 4.531,84 mil toneladas de resíduos, que armazenados nos pátios das usinas siderúrgicas são cosideradas como passivo ambiental, com grande potencial poluidor, o que nos leva a questionar quais utilidades podem ser atribuidas a essa quantidade de passivo ambiental produzido.

A escória de aço é constituída principalmente por $\mathrm{SiO}_{2}, \mathrm{CaO}, \mathrm{Fe}_{2} \mathrm{O}_{3}, \mathrm{FeO}, \mathrm{Al}_{2} \mathrm{O}_{3}, \mathrm{MgO}, \mathrm{MnO}, \mathrm{P}_{2} \mathrm{O}_{5}$, a composição quimica da escória de aço varia de acordo com o tipo de forno, as classes de aço e o método de pré-tratamento, sendo a forma de utilização da escória de aço intimamente relacionada com as suas características químicas e físicas, assim, é necessário investigar e identificar as escórias e seu potencial, observando se essas apresentam características desejáveis e qual sua utilização, quando uma escória possui potencial para utilização agricola, é comum que apresente altos teores de $\mathrm{CaO}$ e $\mathrm{MgO}$ e consideraveis teores de Si solúvel, além de densidade que fascilite a aplicação (densidade alta), baixo custo e baixos teores de contaminantes do solo, como metais pesados, com tais caracteristicas uma escória podera ser utilizada como corretivo de acidez do solo (KORNDÖRFER et al., 2004 a). 


\section{OS DESAFIOS DA GEOGRAFIA FÍSICA NA FRONTEIRA DO CONHECIMENTO \\ Instituto de Geociências - Unicamp \\ Campinas - SP \\ 28 de Junho à 02 de Julho de 2017}

Os corretivos de acidez do solo são produtos capazes de neutralizar a acidez e ainda levar nutrientes essenciais às plantas, principalmente o cálcio e o magnésio. Geralmente os materiais empregados como corretivos de acidez são óxidos, hidróxidos, escórias e carbonatos de Ca e Mg (MALAVOLTA, 1980).

Vários estudos em campo e em casa-de-vegetação têm sido conduzidos para verificar a eficácia dos produtos utilizados como fontes de silício. De modo geral, o que se observa é que fontes de silício, como Wollastonita, escórias de alto forno (CARVALHO-PUPATTO et al., 2003), agregados siderúrgicos, xisto e termofosfato (PEREIRA et al., 2003), proporcionam incrementos nos teores de Ca e Mg trocáveis e uma elevação do $\mathrm{pH}$ do solo, reduzindo a concentração de $\mathrm{Al}^{+3}$ fitotóxico. Além do fornecimento de $\mathrm{Ca}$ e $\mathrm{Mg}$, é importante mencionar que o uso de silicatos aumenta os teores de Si no solo, variando conforme a fonte utilizada.

As escórias que apresentam potencial para uso agricola, mas não apresentam teores expressivos e/ou em concentrações equilibradas de nutrientes para as plantas, diminuindo sua viabilidade de sua utilização, podem receber "aditivos", que fazem com que a escória se torne de maior interesse agronômico, como exemplo, a escória para uso como corretivo de acidez do solo pode receber quantidades extras de Cal virgem agrícola, enriquecendo o material.

Cal virgem agrícola é um produto obtido industrialmente pela calcinação ou queima completa do calcário. Seus constituintes são o óxido de cálcio $(\mathrm{CaO})$ e o óxido de magnésio $(\mathrm{MgO})$, e se apresenta como pó fino. As equações que mostram à reação da cal virgem agrícola no solo demonstram a liberação de $\mathrm{Ca}^{2+}$, $\mathrm{Mg}^{2+}, \mathrm{OH}^{-}$e calor; a liberação de $\mathrm{OH}^{-}$é imediata e total, o que confere à cal virgem o caráter de base forte; e o $\mathrm{OH}^{-}$produzido neutralizará o $\mathrm{H}^{+}$da solução do solo, responsável pela sua acidez (ALCARDE, 2005).

As escórias de siderurgia destacam-se como as principais fontes de silício, tendo como principais componentes os silicatos de cálcio $(\mathrm{CaSiO} 3)$ e de magnésio $(\mathrm{MgSiO} 3)$ sendo estes, os responsáveis pela correção da acidez do solo. Basicamente o mecanismo de correção da acidez pelos silicatos presentes nas escórias pode ser explicado pelas seguintes reações descritas por Alcarde e Rodella (2003):

$$
\begin{aligned}
& \mathrm{CaSiO} 3 \leftrightarrow \mathrm{Ca} 2++\mathrm{SiO} 32- \\
& \mathrm{SiO} 32-+\mathrm{H} 2 \mathrm{O}(\text { solo }) \leftrightarrow \mathrm{HSiO} 3-+\mathrm{OH}-\quad\{1\} \\
& \mathrm{HSiO} 3-+\mathrm{H} 2 \mathrm{O}(\text { solo }) \leftrightarrow \mathrm{H} 2 \mathrm{SiO} 3+\mathrm{OH}-\quad\{2\} \\
& \mathrm{H} 2 \mathrm{SiO} 3+\mathrm{H} 2 \mathrm{O}(\text { solo }) \leftrightarrow \mathrm{H} 4 \mathrm{SiO} 4
\end{aligned}
$$

As equações demonstram que a hidrólise do ânion silicato promove a liberação de hidroxilas (OH-) que no solo reagem neutralizando os prótons $(\mathrm{H}+)$, promovendo a elevação do $\mathrm{pH}$, e ainda reagem com o $\mathrm{Al}^{3+}$ 
presente no solo formando o hidróxido de alumínio $(\mathrm{AlOH})^{3}$, que corresponde a uma forma precipitada e não tóxica aos vegetais e como consequência quanto maior a dose de silicato aplicada, maior o $\mathrm{pH}$ do solo (KORNDÖRFER; GASCHO, 1999 e CARDOSO, 2003).

O presente trabalho teve como objetivo determinar a reatividade de uma escória que recebeu quantidades extras de Cal, enriquecendo o material, ou seja, "aditivo", portado denominada Escória aditivada, em um Latossolo Vermelho Distrófico típico (LVd) e verificar a sua interferência sob o pH e no aumento de Si, $\mathrm{Ca}$ e Mg nesse solo.

\section{Material e Métodos}

Foi realizado um experimento de incubação, o qual foi instalado na Universidade Federal de Uberlândia em local protegido de luz e umidade, com delineamento experimental inteiramente casualizado (ZIMMERMANN, 2004, p.51). A incubação foi realizada no solo: Latossolo Vermelho Distrófico típico $(\mathrm{LVd})$. O solo foi caracterizado quanto aos seus atributos químicos (Tabela I) e físicos (Tabela II).

Tabela I - Análise química do solo utilizado na incubação.

\begin{tabular}{|c|c|c|c|c|c|c|c|c|c|c|}
\hline \multirow[t]{2}{*}{ Solo } & $\mathrm{pH}$ & $\mathrm{P} * * \quad \mathrm{Si}$ & $\mathrm{Al}^{3+}$ & $\mathrm{Ca}^{2+}$ & $\mathrm{Mg}^{2+}$ & SB & $\mathrm{t}$ & CTC & SB & V \\
\hline & & $-\mathrm{mg} \mathrm{dm}{ }^{-3}-$ & \multicolumn{7}{|c|}{ 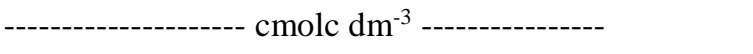 } & $----\%---$ \\
\hline $\mathrm{LVd}$ & 3,9 & 2,8 & 1,1 & 0,2 & 0,1 & 0,4 & 1,5 & 2,4 & 0,4 & 17 \\
\hline
\end{tabular}

Observações: $\mathrm{P}, \mathrm{K}=\left(\mathrm{HCl} 0,05 \mathrm{~N}+\mathrm{H}_{2} \mathrm{SO}_{4}\right.$ 0,025 N); Al, Ca, $\mathrm{Mg}=(\mathrm{KCl} 1 \mathrm{~N})$; M.O. = (Walkley-Black EMBRAPA, 1999); SB = Soma de bases $/ \mathrm{t}=\mathrm{CTC}$ efetiva $/ \mathrm{T}=\mathrm{CTC}$ a pH 7,0 / V = Sat. por Bases $/ \mathrm{m}=$ Sat. por Al.

Tabela II - Análise física do solo utilizado no estudo de incubação.

\begin{tabular}{llcc}
\hline \multirow{2}{*}{ Solo } & Areia Grossa & Areia Fina & Silte \\
& & & Argila \\
\cline { 2 - 4 } & & & \\
\hline LVd - Latossolo Vermelho Distrófico Típico & 73 & 53 & 728 \\
\hline
\end{tabular}

Observações: Análise textural pelo Método da Pipeta (EMBRAPA, 1999).

O Si oriundo da areia é fundido em presença do $\mathrm{NaOH}$ na temperatura de aproximadamente $1.200 \mathrm{C}$ até a formação do silicato de sódio (processo executado em usina siderúrgica). O silicato de sódio então é reagido com o ácido sulfúrico para produção da sílica gel - $\mathrm{SiO}_{2}$. Este último processo gera uma água de lavagem ácida, que é neutralizada com cal $\left[\mathrm{Ca}(\mathrm{OH})_{2}\right]$. Os sólidos gerados neste processo de neutralização 
são constituídos de $\mathrm{CaSO}_{4} \times \mathrm{H}_{2} \mathrm{O}$ mais sílica $\left(\mathrm{SiO}_{2}\right)$ o qual passa por um processo de filtragem para remoção da parte líquida finalizando o processo, formando a Escória.

A Escória é um produto formado por compostos de $\mathrm{Si}$ na forma de $\mathrm{SiO}_{2}, \mathrm{Ca}$ na forma de $\mathrm{Ca}(\mathrm{OH})_{2}$ e $\left.\mathrm{CaSO}_{4} \cdot \mathrm{xH}_{2} \mathrm{O}\right)$ e $\mathrm{Mg}$ na forma de $\mathrm{Mg}(\mathrm{OH})_{2}$. Os sólidos se apresentam na forma de grãos de reduzida granulometria, variando da forma pastosa a sólida, dependendo do seu teor de umidade. A cor predominante é cinza. A Escória recebe posteriormente quantidades extras de Cal enriquecendo o material com Ca e Mg, produzindo a Escória aditivada. Assim foram testados os produtos indicados na Tabela III, sendo que os mesmos foram caracterizados quanto a seus teores Si total, Si solúvel, conforme metodologia descrita por Korndörfer et al, (2004b), teores de CaO e MgO segundo EMBRAPA (1999) (Tabela III). Os produtos testados foram moídos até passar 100\% em peneira de 50 mesh (malhas/polegada). As doses do produto Escória aditivada (fonte de $\mathrm{Si}$ ) adicionada ao solo foi baseada no teor de Si total da fonte.

Para efeito de comparação tanto para as avaliações com relação aos elementos $\mathrm{Si}, \mathrm{Ca}$ e $\mathrm{Mg}$ quanto para o efeito sobre o $\mathrm{pH}$ do solo, utilizou-se a Wollastonita, que corresponde a um produto mundialmente empregado em estudos com silício, classificado como um metassilicato de cálcio natural de alto grau de pureza.

Tabela III - Caracterização química da Escória aditivada e do padrão Wollastonita utilizados no experimento.

\begin{tabular}{|c|c|c|c|c|}
\hline FONTES & Si Total & Si Solúvel* & $\mathrm{CaO}$ & $\mathrm{MgO}$ \\
\hline & \multicolumn{4}{|c|}{----------------------\%o--------------------- } \\
\hline Escória aditivada & 15,8 & 3,6 & 24,53 & 13,46 \\
\hline Wollastonita (padrão) & 20,7 & 4,6 & 42,4 & 1,9 \\
\hline
\end{tabular}

* Extração com $\mathrm{NH}_{4} \mathrm{NO}_{3}+\mathrm{Na}_{2} \mathrm{CO}_{3}$

Fontes de nutrientes para as culturas devem ser analisadas quanto aos teores de metais pesados em sua constituição, podendo ou não ser limitado seu uso em solos agrícolas, pois seu acúmulo é preocupante e existe grande risco de serem transferidos para as diferentes espécies de plantas.

A Escória aditivada foi caracterizada quanto à sua concentração de metais pesados (Tabela IV), sendo os teores encontrados aceitos para a sua utilização como fertilizante. 
Tabela IV - Caracterização química quanto à presença de metais da Escória aditivada.

\begin{tabular}{lllll}
\hline Parâmetros & Unidade & Resultados & Obs. & L.D. (1) \\
\hline $\mathrm{Ni}$ & $\mathrm{ppm}$ & 12,0 & - & 1,0 \\
$\mathrm{Cd}$ & $\mathrm{ppm}$ & $<$ L.D. & abaixo do L.D. & 0,5 \\
$\mathrm{~Pb}$ & $\mathrm{ppm}$ & 7,5 & - & 1,0 \\
\hline
\end{tabular}

(1) L.D. Limite de detecção do método

A Tabela $\mathrm{V}$ demostra a média da concentração de metais pesados encontrados naturalmente em Latossolos do Estado de Minas Gerais (CAIRES, 2009).

Tabela V - Teores naturais de metais pesados em Latossolos do Estado de Minas Gerais.

\begin{tabular}{llll}
\hline Parâmetros & Unidade & Resultados (médias) & Obs. \\
\hline $\mathrm{Ni}$ & $\mathrm{ppm}$ & 46,65 & $-\mathrm{n}=68$ \\
$\mathrm{Cd}$ & $\mathrm{ppm}$ & 0,36 & $-\mathrm{n}=68$ \\
$\mathrm{~Pb}$ & $\mathrm{ppm}$ & 1,04 & $-\mathrm{n}=68$ \\
\hline
\end{tabular}

Fonte: Adapdado de Caires (2009).

\subsection{Tratamentos}

Ao solo foi incorporado às fontes de silício (Wollastonita e Escória aditivada), as doses adicionadas foram determinadas com base nos teores de $\mathrm{Si}$ total das fontes e consistiram em doses crescentes, que equivaleram a 200 e $400 \mathrm{~kg} \mathrm{ha}^{-1}$ de Si para a Wollastonita e para Escória aditivada, de modo que com os resultados do tratamento padrão (Wollastonita) fosse possível obter uma comparação com a Escória aditivada (Tabela VI).

O solo recebeu doses de Si proveniente da fonte padrão (Wollastonita), pois a partir dessa fonte foi possível fazer a correspondência de reatividade para o produto testado.

A Wollastonita $\left(\mathrm{CaSiO}_{3}\right)$ é comercializado com o nome de Vansil - EW 20. De acordo com o fabricante, apresenta a seguinte composição química: $\mathrm{SiO}^{2}=51,9 \% ; \mathrm{CaO}=42 \%$ ou $(30 \% \mathrm{Ca}) ; \mathrm{MgO}=1,5 \% ; \mathrm{Al}_{2} \mathrm{O}_{3}=$ $1,8 \% ; \mathrm{Na}_{2} \mathrm{O}=0,3 \% ; \mathrm{Fe}_{2} \mathrm{O}_{3}=0,3 \% ; \mathrm{pH}=9,8$ (sol. $10 \%$ ); $\mathrm{MnO}=0,03 \%$; densidade = 2,9 kg/m³ ; peso molecular $=116$; ponto de fusão $=1540{ }^{\circ} \mathrm{C}$. 
Tabela VI - Doses de Si e dos produtos utilizados (estudo de incubação).

\begin{tabular}{llllll}
\hline & & $\mathrm{Si}$ & $\mathrm{Si}$ & Dose & Dose \\
Fonte/Material $(*)$ & Dose & Total & Solúvel & Fonte/ & Fonte/ \\
& $\mathrm{Si}$ & fonte/ & $\begin{array}{l}\mathrm{NH}_{4} \mathrm{NO}_{3} \\
+\mathrm{Na}_{2} \mathrm{CO}_{3}\end{array}$ & Material & Material \\
& & Material & & & \\
\hline & $\mathrm{kg} \mathrm{ha}^{-1}$ & $\%$ & $\%$ & $\mathrm{~kg} \mathrm{ha}^{-1}$ & $\mathrm{~g} / 300 \mathrm{~g}$ solo \\
Wollastonita (padrão $\mathrm{Si})$ & 200 & 21,0 & 4,6 & 952,4 & 0,143 \\
Wollastonita (padrão $\mathrm{Si})$ & 400 & 21,0 & 4,6 & 1904,8 & 0,286 \\
Escória aditivada & 200 & 15,8 & 3,6 & 1265,8 & 0,190 \\
Escória aditivada & 400 & 15,8 & 3,6 & 2531,7 & 0,380 \\
\hline
\end{tabular}

Os produtos Escória aditivada e a Wollastonita foram misturados com $300 \mathrm{~g}$ de solo seco ao ar e peneirado, dentro de um saco plástico. Após a mistura, o solo foi colocado em recipientes plásticos (potes). Adicionando-se água destilada em quantidades iguais em cada recipiente e de acordo com a capacidade de retenção de água do solo.

Depois de 30 e 60 dias de reação com o solo (período de incubação), foi retirada uma amostra de solo de aproximadamente $50 \mathrm{~g}$ de cada recipiente. As amostras foram identificadas, secas e analisadas quanto aos teores de Si solúvel, pelo método de extração em $\mathrm{CaCl}_{2}, 0,01 \mathrm{~mol} \mathrm{~L}{ }^{-1}$, conforme metodologia descrita por Korndörfer et al., (2004b). As análises de $\mathrm{pH}$ em $\mathrm{CaCl}_{2}$ 0,01mol L $\mathrm{m}^{-1}$, Ca e $\mathrm{Mg}$ trocáveis seguiram a metodologia descrita pela EMBRAPA (1999).

Com relação aos resultados obtidos, foi feita a análise do desempenho da Escória aditivada e Wollastonita, utilizando o teste de Tukey (ZIMMERMANN, 2004, p.37), com comparação entre as medias ao nível de 5\% de probabilidade e auxílio do programa SISVAR (FERREIRA, 2008), sendo a média das duas doses (200 e $\left.400 \mathrm{~kg} \mathrm{ha}^{-1}\right)$ de cada fonte no solo. 


\section{Resultados e Discussão}

\subsection{Avaliação da Escória aditivada como fontes de Si}

No solo estudado tanto aos 30 quanto aos 60 dias, a fonte mais eficiente em disponibilizar Si foi a Escória aditivada (Tabela VII), o que mostra a boa reatividade da fonte testada. A maior liberação de Si pela fonte teste, no solo estudado, mostra a boa solubilidade do produto, o que provavelmente irá se refletir na absorção deste elemento pelas plantas (RAMOS, 2005).

Em ambos os solos, os teores de $\mathrm{Si}$ apresentaram-se maiores na primeira coleta, isto é, 30 dias após o início da incubação (Tabela VII), isso demonstra que praticamente toda reação do produto aconteceu nos primeiros 30 dias o que indica uma disponibilidade rápida pelas fontes podendo ser usada em culturas de ciclo curto (ARAÚJO, 2007).

Tabela VII. Teores de Si no solo, extraídos com $\mathrm{CaCl}_{2}\left(0,01 \mathrm{~mol} \mathrm{~L}^{-1}\right)$, após 30 e 60 dias de incubação.

\begin{tabular}{|c|c|c|}
\hline \multirow{4}{*}{ Fontes } & \multicolumn{2}{|c|}{$\mathrm{LVd}$} \\
\hline & \multicolumn{2}{|c|}{ Média das doses } \\
\hline & 30 dias & 60 dias \\
\hline & ---------------------------- T & ------------ \\
\hline Wollastonita & $10,84 \mathrm{~b}$ & $7,39 \mathrm{~b}$ \\
\hline Escória aditivada & $11,39 \mathrm{a}$ & $7,98 \mathrm{a}$ \\
\hline
\end{tabular}

Médias seguidas de mesma letra na coluna não distinguem entre si (Tukey 5\%)

\subsection{Avaliação da Escória aditivada como corretivos de acidez}

A presença do silicato $\left(\mathrm{SiO}_{3}{ }^{-2}\right)$ é capaz de neutralizar os prótons $\left(\mathrm{H}^{+}\right)$, segundo a equação descrita por Alcarde (1992), o que resulta em um efeito sobre o pH do solo e consequentemente quanto maior a dose de silicato aplicada, maior o pH do solo (KORNDÖRFER; GASCHO, 1999 e CARDOSO, 2003).

A Wollastonita e a Escória aditivada não diferiram estatisticamente quanto a eficiência na correção do pH do Latossolo Vermelho Distrófico típico, aos 30 dias após a incubação (Tabela VIII), o que demonstra a rápida reatividade destas fontes neste solo.

Avaliando-se a média entre as doses de cada fonte, pode-se observar que a Wollatonita obteve uma melhor desempenho aos 60 dias de incubação, porem não há diferença estatistica, demonstrando a eficiência da Escória aditivada na correção do acidez do Latossolo Vermelho Distrófico típico (Tabela VIII). 
Tabela VIII. pH em $\mathrm{CaCl}_{2}\left(0,01 \mathrm{~mol} \mathrm{~L}^{-1}\right)$, após 30 e 60 dias de incubação do solo.

\begin{tabular}{lcc}
\hline \multirow{2}{*}{ Fontes } & \multicolumn{2}{c}{ LVd } \\
\cline { 2 - 3 } & \multicolumn{2}{c}{ Média das doses } \\
\cline { 2 - 3 } & 30 dias dias \\
\cline { 2 - 3 } & $3,8 \mathrm{a}$ & $4,0 \mathrm{a}$ \\
Wollastonita & $3,8 \mathrm{a}$ & $3,9 \mathrm{a}$ \\
\hline
\end{tabular}

Médias seguidas de mesma letra na coluna não distinguem entre si (Tukey 5\%)

\subsection{Avaliação da Escória aditivada como fontes de Ca e Mg}

Após 60 dias do início do período de incubação, o incremento nas doses de Wollastonita e escória aditivada proporcionou um aumento significativo nos teores de Ca no solo. O que já era esperado em função da alta concentração de óxido de cálcio presente nestas fontes (Tabela III), concordado com dados obtidos por Ramos (2005) para a fonte Wollastonita.

Comparando-se a Escória aditivada com a Wollastonita, por meio da média entre as doses $(200$ e $400 \mathrm{~kg}$ $\mathrm{ha}^{-1}$ ), os teores de $\mathrm{Ca}$ e $\mathrm{Mg}$ no solo após 30 e 60 dias de incubação refletem fundamentalmente a composição destes produtos, isto é, a Wollastonita, rica em Ca apresentou maior aumento nos teores deste nutriente em comparação com a Escória aditivada diferindo estatisticamente apenas aos 60 dias após incubação do Latossolo Vermelho Distrófico típico (Tabela IX), concordado com os dados obtidos por Araújo (2007). Já para os teores de Mg a Escória aditivada apresentou melhor desempenho, isto devido a sua alta concentração em óxido de magnésio diferindo estatisticamente da Wollastonita (Tabela X).

A maior concentração de $\mathrm{Mg}$ nos silicatos implica na sua utilização em solos com baixos teores de $\mathrm{Mg}$ (0,5 $\left.\mathrm{cmolcdm}^{-3}\right)$, podendo, assim, agir semelhantemente ao calcário dolomítico (RAMOS, 2005).

Tabela IX. Teores de Ca, 30 e 60 dias após o início da incubação.

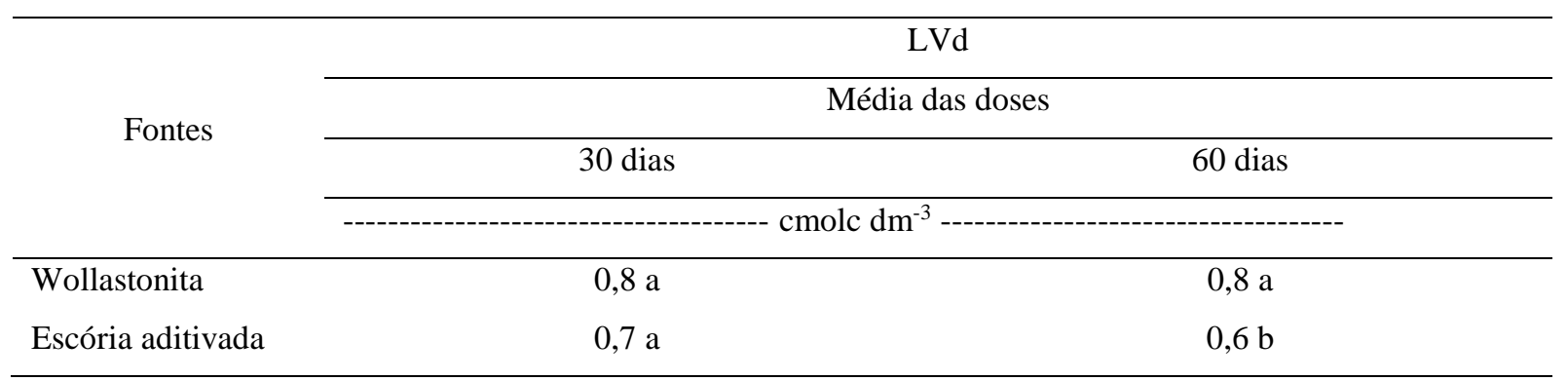

Médias seguidas de mesma letra na coluna não distinguem entre si (Tukey 5\%) 
Tabela X. Teores de Mg, 30 e 60 dias após o início da incubação.

\begin{tabular}{lcc}
\hline Fontes & \multicolumn{2}{c}{ LVd } \\
\cline { 2 - 3 } & \multicolumn{2}{c}{ Média das doses } \\
\cline { 2 - 3 } & \multicolumn{2}{c}{60 dias } \\
\cline { 2 - 3 } & $0,1 \mathrm{~b}$ & $0,1 \mathrm{~b}$ \\
\hline Wollastonita & $0,4 \mathrm{a}$ & $0,5 \mathrm{a}$
\end{tabular}

Médias seguidas de mesma letra na coluna não distinguem entre si (Tukey 5\%)

\section{Considerações Finais}

As fontes, Escória aditivada possui maior eficiência em disponibilizar Si e Mg no Latossolo Vermelho Distrófico típico diferindo estatisticamente da Wollastonita, a Escória aditivada e a Wollastonita apresentaram desempenhos semelhantes quanto à elevacão do $\mathrm{pH}$ do solo, não havendo diferenças estatisticas, a Escória aditivada e a Wollastonita não diferiram estatisticamnete quanto ao fornecimento de $\mathrm{Ca}$ ao solo aos 30 dias, diferindo estatisticamente apenas aos 60 dias, com melhor desempenho da Wollastonita;

Com a adição de Cal virgem agrícola, a Escória foi capaz de obter resultados proximos ao desempenho demosntardo pela fonte teste Wollastonita, possibilitando boa eficiência na disponibilização de Si, Ca e $\mathrm{Mg}$, o que nos mostra a importância da pesquisa qualitativa com posterior análise empírica dos resultados, pois a Escória não obteve resultados satisfatorios em seus testes anteriores, mas demonstrou potencial para utilização agrícola, com isso foi realizado sua "aditivação" e diante dos resultados obeservamos que seu potêncial foi explorado, garantindo assim sua utilização agrícola;

Escórias de siderurgia apresentam teores consideráveis de metais pesados, porém neste trabalho a escória estudada apresenta menor concentração de $\mathrm{Pb}$ do que a naturalmente encontardos em Latossolos do Cerrado e ficou abaixo do limite de detecção do método para quantificação dos teores de Cd.

\section{Bibliografia}

ALCARDE, J.A.; RODELLA, A.A. Qualidade e legislação de fertilizantes e corretivos. In: CURI, N.; MARQUES, J.J.; GUILHERME, L.R.G.; LIMA, J.M. de; LOPES, A. S.; ALVARES V., V.H. (ed). Tópicos em Ciência do Solo. Viçosa: Sociedade brasileira de Ciência do Solo, 2003. p. 291-334.

ALCARDE, J.C. Corretivos da acidez dos solos: características e interpretações técnicas. São Paulo, Associação Nacional para Difusão de Adubos e Corretivos Agrícolas, 1992. 26 p. (Boletim Técnico, 6).

ALCARDE, J.C. Corretivos da acidez dos solos: características e interpretações técnicas. São Paulo, Associação Nacional para Difusão de Adubos e Corretivos Agrícolas, 2005. 24p. (ANDA, Boletim Técnico, 6) 
ARAÚJO, L. S. Viabilidade do uso da "escória transformada" como corretivo de acidez do solo e fonte de Si, Ca e Mg. Ano 2007. 39f . Monografia (Graduação em agronomia) - Instituto de Ciências Agrárias - Universidade Federal de Uberlândia, Uberlândia, Ano 2007.

ALLOWAY, B. J. Heavy metals in soils. 2aed. Londres: Springer, 368 p., 1995.

CAIRES, S. M. Determinação dos teores naturais de metais pesados em solos do Estado de Minas Gerais como subsídio ao estabelecimento de valores de referência de qualidade. 2009. 304f. Tese (Doutorado em Solos e Nutrição de Plantas) - Instituto de Ciências Agrárias, Universidade Federal de Viçosa, Viçosa.

CARDOSO, K. Aplicação de silicato de cálcio na recuperação de pastagem degradada de Brachiaria decumbens. 2003. 48f. Monografia (Graduação em agronomia) - Instituto de Ciências Agrárias, Universidade Federal de Uberlândia, Uberlândia, 2003.

CARVAlHO-PUPATTO, J. G.; BULL, L. T.; CRUSCIOL, C. A. C.; MAUAD, M.; SILVA, R. H. Efeito de escória de alto forno no crescimento radicular e na produtividade de arroz. Pesquisa agropecuária brasileira, Brasília, DF v. 38, n. 11, p. 1323-1328, nov. 2003.

DELLA, V. P., JUNKES, J. A., KUHN, I., HIELLA, H. G., HOTZA, D. Utilização do subproduto da recuperação metálica de escórias de aços inoxidáveis na síntese de pigmentos cerâmicos: caracterização da matéria-prima. Cerâmica, São Paulo, v.51, n. 318, p. 111-116, 2005.

EMPRESA BRASILEIRA DE PESQUISA AGROPECUÁRIA. Centro Nacional de pesquisa de solos (Rio de Janeiro-RJ). Manual de métodos de análise de solo. 2. ed.rev. atual. Rio de Janeiro, 1999. 212 p.

FERREIRA, D. F. SISVAR: um programa para análises e ensino de estatística. Revista Científica Symposium, Lavras, v.6, n.2, p.36-41, 2008.

GUIMARÃES, J. E. P. Escórias na fertilidade do solo. Instituto Geográfico e Geológico de São Paulo. Brasil, 1967. 42p.

INSTITUTO AÇO BRASIL. Estatística preliminar. Rio de Janeiro, n.22, 2016, 10p.

KORNDÖRFER, G.H.; GASCHO, G.J. Avaliação de fontes de silício para o arroz. In: CONGRESSO BRASILEIRO DE ARROZ IRRIGADO, 1.; REUNIÃO DA CULTURA DO ARROZ IRRIGADO, 23., Pelotas, 1999. Anais... Pelotas, EMBRAPA Clima Temperado, 1999. p.313-316.

KORNDÖRFER, G.H.; PEREIRA, H.S.; CAMARGO, M.S. Silicatos de Cálcio e magnésio na agricultura. 3. ed. Uberlândia: GPSi/ICIAG/UFU, Boletim Técnico; 01. 2004a. 23 p.

KORNDÖRFER, G.H.; PEREIRA, H.S.; NOLLA, A. Análise de silício: solo planta e fertilizante. Uberlândia, GPSi-ICIAG-UFU, Boletim Técnico; 02. 2004b. 50 p.

MALAVOLTA, E. Elementos de nutrição de plantas. Piracicaba: Agronômica Ceres, 1980. 251p.

PEREIRA, H.S.; VITTI, G.C., KONDÖRFER, G.H. Comportamento de diferentes fontes de Silício no solo e na cultura do tomateiro. Revista Brasileira de ciência do solo, Lavras, n.27, p. 101-108, 2003.

RAMOS, L.A. Reatividade de fontes de silício e sua eficiência na absorção e acumulação na cultura do arroz irrigado. 2005. 63f. Dissertação (Mestrado em Agronomia) - Universidade Federal de Uberlândia, Uberlândia, 2005 .

SEIFFERT, M. E. B. Gestão ambiental: instrumentos, esferas de ação e educação ambiental. 1. Ed. São Paulo: Atlas, 2009. 310 p.

ZIMMERMANN, F. J. P. Estatística aplicada à pesquisa agrícola. Santo Antônio de Goiás: Embrapa Arroz e Feijão, 2004, 402p. 